\title{
Inclusão: percursos e experiências educacionais no Brasil e na Itália
}

\section{Inclusion: educational experiences and journeys in Brazil and in Italy}

\section{Resumo:}

Considerando a inclusão como um tema de discussão atual e movimento de cunho internacional, o presente estudo se refere a dois diferentes modelos e experiências educacionais inclusivas. Realiza, a apresentação e a análise dos percursos, experiências educacionais e características que definem o processo que ocorre no Brasil e na Itália, na atualidade. A partir da pesquisa e análise de publicações referentes ao tema se torna possível inferir que os dois países se encontram inseridos no movimento mundial de inclusão social, possuindo elementos históricos, referências legais e acadêmicas que caracterizam seus diferentes caminhos. A discussão teórica destaca aspectos centrais, sem pretender esgotar o tema ou menosprezar detalhes e dimensões, mas com a intenção de trazer ao campo científico elementos para ampliação da reflexão, a partir dos diferentes modelos e formas de efetivação da educação na perspectiva da inclusão.

Palavras-chave: Educação Inclusiva. Educação Especial. Inclusão Social.

\begin{abstract}
Considering inclusion as a theme currently in discussion and an international movement, this paper we refer to two different inclusive educational experiments and models. Presents and analyze the paths, educational experiences and characteristics that define the processes that take place in Brazil and in Italy. Based on research and analysis of publications on this topic, becomes possible to infer that both countries are inserted in the worldwide movement towards social inclusion, where as there are historical elements, legal and academic references that characterize their different paths. The theoretical discussion highlights central aspects in the discussion, with no intent to cover it exhaustively or overlook details and dimensions, but with the intention of bringing to the scientific field elements to enlarge reflection from different models and ways of fostering education under the perspective of inclusion. Keywords: Inclusive Education. Special Education. Social Inclusion.
\end{abstract}

SCUSSIATTO, Caroline Carminatti. Inclusão: percursos e experiências educacionais no Brasil e na Itália. Informática na Educação: teoria e prática, Porto Alegre, v. 18, n. 2, p. 19-37, jul./dez. 2015.

\section{Caroline Carminatti Scussiatto}

\section{Educação na Perspectiva da In- clusão: uma proposição mundial}

U m olhar atento ao perfil mundial da atualidade pode permitir a verificação de modificações no cotidiano social. Visualizamos e convivemos com diferentes exposições de modos de ser, agir, pensar, sentir, expressar, estar e ocupar espaços significativos em todas as instâncias. Tal realidade demanda que se amplie a visão acerca das diferenças e tem promovido reflexões sobre os movimentos vivenciados mundialmente e sobre o avanço da perspectiva do incluir.

A inclusão, enquanto processo político, social, cultural e pedagógico, tem ocupado lugar de destaque no Brasil e no mundo. Diversos aspectos fazem parte dos debates e das ações que buscam o ato de incluir em sua totalidade. Passerino e Montardo (2007) constroem um conceito de inclusão que contribui para essa compreensão pois, partindo da análise de di- 
versos referenciais, englobam e enfatizam o caráter multidimensional da inclusão:

Considera-se inclusão, portanto, o processo estabelecido dentro de uma sociedade mais ampla que busca satisfazer necessidades relacionadas com qualidade de vida, desenvolvimento humano, autonomia de renda e equidade de oportunidades e direitos para os indivíduos e grupos sociais que em alguma etapa de sua vida encontram-se em situação de desvantagem com relação a outros membros da sociedade. (PASSERINO; MONTARDO, 2007, p. 4)

Rahme (2013) afirma que se vive um processo de inclusão articulado a um movimento mais amplo de internacionalização de direitos, afirmados a partir das legislações que generalizam tal condição. Tratados internacionais, como a Carta Universal dos Direitos Humanos da ONU (1948), a Declaração Mundial sobre a Educação para Todos (UNESCO, 1990), Declaração de Salamanca (BRASIL, 1994), Convenção de Guatemala (OEA, 1999), Convenção Internacional sobre os Direitos das Pessoas com Deficiência (ONU, 2006), são marcos e diretrizes orientadoras desse percurso.

Esses documentos trazem à pauta das mudanças a diferença como valor humano irrefutável e o processo de incluir, em sua integralidade, como agente de condições plenas para o desenvolvimento das potencialidades de todos os seres humanos, em sua singularidade. Além disso, apontam a necessidade de acesso, permanência e qualidade em todos os âmbitos de vivência e convivência dos sujeitos, ou seja, de reconhecimento, aceitação e pertencimento social e educacional.

A educação é um dos eixos inseridos nos diálogos sobre inclusão social, bem como dos modelos e experiências de inclusão que têm sido vivenciados mundialmente. Trata-se de um fenômeno essencialmente humano, que surge da construção histórica e social da ação do homem sobre a natureza e que proporciona mudanças, podendo ser um dos caminhos para estender e validar o conceito de cidadania para todos e a aceitação do diverso.

Valentini e Bisol argumentam:

A educação inclusiva tem como princípios: a aceitação das diferenças com ênfase nas potencialidades; a valorização da diversidade humana; o respeito mútuo; o direito de pertencer versus o status de pertencer; o aprendizado cooperativo e a confiança no aprendizado mútuo entre os estudantes. Esse novo entendimento destaca a pessoa como um todo em relação aos fatores contextuais e do meio, ressituando-a entre os demais e rompendo o isolamento. (VALENTINI; BISOL, 2012, p. 14)

A Declaração dos Direitos Humanos (ONU, 1948) foi um dos documentos que trouxe a ideia inicial de que todos são diferentes em suas características e iguais em seus direitos. A partir da sua promulgação, os movimentos em prol do olhar sobre as diferenças e do reconhecimento, aceitação e práticas sociais e educativas, legislações e políticas públicas diferenciadas foram sendo inseridos amplamente no cenário das relações sociais e das discussões.

Na década de noventa, na Declaração Mundial de Educação para Todos (UNESCO, 1990) e na Declaração de Salamanca (BRASIL,1994), lançou-se a base para a política de inclusão nos sistemas formais de ensino, impulsionando mundialmente a proposta da educação inclusiva.

Insere-se, assim, uma proposição mundial de inclusão, entendida como a posição político-filosófica de superar as condições de marginalização socioeconômicas e culturais de indivíduos e/ou populações, sob a premissa de que 
melhores condições de vida para todos decorrem do viver em sociedades mais igualitárias. (UNESCO, 2003)

Diante desse contexto e buscando caminhos para a consecução desse ideal, os países vêm construindo diferentes abordagens, de formas diversificadas dentro de suas realidades históricas, sociais, políticas e econômicas. A seguir serão apresentados nesse artigo, a partir de levantamento e análise de documentos e publicações referentes a esses percursos, as experiências educacionais e características que definem os processos no Brasil e na Itália.

\section{Educação Inclusiva no Brasil}

Os movimentos políticos e sociais mundiais impulsionaram e direcionaram o percurso da educação na perspectiva inclusiva no Brasil. Os estudos de Rahme (2013) indicam que a partir da primeira metade da década de noventa os movimentos inclusivos evidenciaram-se, ampliando-se paulatinamente a partir de 2000 (KASSAR, 2011).

Através de um processo que vem sendo construindo a partir das diretrizes legais, observamos avanços na busca da superação de um modelo educacional que contemplava a igualdade e a uniformidade como padrão e a exclusão como consequência, evoluindo para um pressuposto que conhece, compreende, aceita e valoriza a diversidade dos alunos segundo suas exigências biopsicossociais, assegurando êxito na aprendizagem e na participação (CARVALHO, 2004).

Houve diversas fases na caminhada histórica da implantação da educação inclusiva no Brasil, nas quais a díade inclusão/exclusão foi vivenciada e praticada com diferentes significações. Beyer (2009) cita quatro momentos históricos do contexto educativo brasileiro: exclusão do sistema escolar (as escolas serviram a um tipo de seleção); atendimento especial no sistema escolar (surgimento de escolas especiais para as crianças com deficiência); integração no sistema escolar regular (crianças foram inseridas no sistema educacional tradicional) e; inclusão no sistema escolar regular (atendimento a todas as crianças, sem qualquer exceção, garantindo direito a uma educação de qualidade a todos). Esta é a etapa que se encontra em construção na atualidade, a qual apresenta descompassos e vulnerabilidades.

Sanchez (2005) diferencia os momentos de integração e inclusão. Refere que na perspectiva da integração houve um movimento físico dos estudantes com deficiência das escolas especiais para as escolas regulares, sendo que o enfoque educativo permaneceu deficitário, individualista, com cunho médico, enfatizando a deficiência e onde o estudante deveria buscar integrar-se ao contexto educativo. A inclusão busca o fim dos rótulos e pauta-se em um plano de trabalho mais amplo de melhorias políticas, culturais e de práticas escolares, que defende a busca da igualdade e excelência para todos os alunos, respeito e valorização às diferenças, bem como propõe ações cooperativas e atuação reflexiva.

A Constituição Federal de 1988 definiu a obrigatoriedade do ensino fundamental de oito anos e no artigo 208 garantiu o atendimento educacional especializado como dever do Estado, preferencialmente oferecido na rede regular de ensino. A Lei no 9.394/96 - nova Lei de Diretrizes e Bases da Educação Nacional apresenta um capítulo específico à educação especial, compreendida como a modalidade de educação escolar oferecida preferencialmente na rede regular de ensino para estudantes por- 
tadores de necessidades especiais. Também prescreve o atendimento educacional em classes, escolas ou serviços especializados para os casos nos quais não seja possível a integração no ensino comum.

Em 1994 a Secretaria de Educação Especial do Ministério da Educação (SEESP/MEC) lançou a Política Nacional de Educação Especial. (BRASIL, 1994). A partir dessa política, segundo Rahme (2013), a Educação Especial é preconizada por princípios de integração e não apresenta elementos de perspectiva inclusiva.

A partir de então surgiram movimentos como a Resolução no 2 do Conselho Nacional de Educação/Câmara de Educação Básica (CNE/CEB) de 2001, que institui as Diretrizes Nacionais para a Educação Especial na Educação Básica, assegurando: os sistemas de ensino devem passar a matricular todos os alunos; as escolas devem receber estudantes com necessidades educacionais especiais e organizarem-se para tal; o professor especializado em educação especial tem a função de acompanhar e dar suporte aos professores das escolas comuns, promovendo a inclusão escolar (BRASIL, 2001).

A Educação Especial é definida no artigo 30 da Resolução, como modalidade da educação escolar, processo educacional definido por uma proposta pedagógica que assegure recursos e serviços educacionais especiais, organizados institucionalmente para apoiar, complementar, suplementar e, em alguns casos, substituir os serviços educacionais comuns. O objetivo é garantir a educação escolar e promover o desenvolvimento das potencialidades dos educandos que apresentam necessidades educacionais especiais, em todas as etapas e modalidades da educação básica.

Garcia (2013) refere que essa resolução introduz a Educação Especial na Educação Básica e a caracteriza como apoio pedagógico especializado à classe comum e prevê a substituição da classe comum.

Rahme (2013) considera que esse movimento, por um lado, suscita a discriminação e não-totalidade inclusiva da proposta. Por outro lado, promove espaços que preservam igualdade de oportunidades às crianças com deficiência que são excluídas das práticas das escolas comuns. Além disso, pouco se evidencia o movimento de articulação entre os setores públicos, bem como entre famílias, escola e sociedade.

No decorrer da década compreendida entre 2001 e 2010, observam-se orientações inclusivas na política de educação especial no Brasil. Garcia (2013, p. 101) alude a esse período como "[...] prenhe em eventos e significados [...]" para a política educacional inclusiva.

Em 2007 foi lançado o Programa de Implementação das Salas de Recursos Multifuncionais (SEM), com o objetivo de apoiar os sistemas de ensino na organização e oferta do Atendimento Educacional Especializado (AEE). Esses são espaços dotados de equipamentos, mobiliários e materiais didáticos e pedagógicos para a oferta do AEE. Segundo Garcia (2013), - AEE passa de modalidade ampla para modalidade de atendimento privilegiada nas SRM.

Em 2008 ocorreu o lançamento da Política Nacional de Educação Especial na Perspectiva da Educação Inclusiva (BRASIL, 2008), influenciado por documentos internacionais, como a Convenção de Guatemala (OEA, 1999) e de Nova Iorque (ONU, 2006). A resolução no 4, de 2009, institui Diretrizes Operacionais para o Atendimento Educacional Especializado na Educação Básica na modalidade Educação Especial. Redefine $A E E$, considerado como modalidade de ensino que perpassa todos os níveis, etapas e modalidades, realiza o atendimento 
educacional especializado, disponibiliza os recursos, serviços e orienta quanto a sua utilização no processo de ensino-aprendizagem nas turmas comuns do ensino regular.

Para Garcia (2013), essa proposta ultrapassa a dimensão de apoio e assume o espaço de complementaridade e suplementaridade, através da disponibilização de recursos e serviços à escola comum.

O público alvo do AEE se tornou restritivamente mais definido, sendo classificado através de diagnósticos da seguinte forma:

a) Alunos com deficiência: aqueles que têm impedimentos de longo prazo de natureza física, intelectual, mental ou sensorial;

b) Alunos com transtornos globais do desenvolvimento: aqueles que apresentam um quadro de alterações no desenvolvimento neuropsicomotor, comprometimento nas relações sociais, na comunicação ou estereotipias motoras. Incluem-se nessa definição alunos com autismo clássico, síndrome de Asperger, síndrome de Rett, transtorno desintegrativo da infância (psicoses) e transtornos invasivos sem outra especificação;

c) Alunos com altas habilidades/superdotação: aqueles que apresentam um potencial elevado e grande envolvimento com as áreas do conhecimento humano, isoladas ou combinadas - intelectual, liderança, psicomotora, artes e criatividade (BRASIL, 2009).

Para Garcia (2013), nesse aspecto há uma restrição dos grupos que constituem a categoria necessidades educativas especiais, conforme o MEC. Além disso, os artigos 12 e 13 estabelecem que o professor do AEE deverá ter formação específica para a Educação Especial e esclarecem as atribuições desse profissional. 0 modelo de atendimento proposto transforma o professor de Educação Especial em profissional multifuncional, que se torna gestor de recursos de aprendizagem, minimizando a essência da ação docente.

Ressalta-se também o estudo de Chagas (2006), que apresenta de forma detalhada e ampliada todas as ações no âmbito de saúde, educação, assistência social, recursos humanos e formação profissional e do trabalho no Brasil. Aponta as regulações dos direitos constitucionais, investimentos financeiros e programas de desenvolvimento elaborados nessas áreas. Relata a existência e a finalidade da Coordenadoria Nacional para Integração da Pessoa Portadora de Deficiência (CORDE) desde 2005, órgão vinculado à Subsecretaria de Direitos Humanos e subordinado à Secretaria Geral da Presidência, cuja finalidade é articular, normalizar, coordenar e planejar ações e medidas governamentais que se referem às pessoas com deficiência, visando assegurar o exercício pleno dos direitos básicos estabelecidos na Constituição e nas leis.

Porém, ao mesmo tempo em que a autora apresenta e descreve as normativas e movimentos, afirma que sua existência não é efetiva para a concretização do exercício dos direitos sociais, pois existem obstáculos materiais e sociais, arranjos tributários e distributivos restringidos, falta de alternativas de focalização dos atendimentos, falta de estrutura física e equipes técnicas adequadas à demanda $(\mathrm{CHA}-$ GAS, 2006).

Apresentadas as orientações normativas e caminhos percorridos no modelo inclusivo de educação no Brasil, que apresenta iniciativas legislativas, arcabouço legal, estruturas definidas, percebe-se que o país está iniciando o exercício de tais ações, com dificuldades de implementação e efetivação qualitativa dos ensejos inclusivos. 


\section{Educação Inclusiva na Itália}

A inclusão configurou-se como diretriz fundamental para toda a educação nacional italiana desde a década de 1970 e vem permanecendo na perspectiva de continuidade, sendo modelo internacionalmente reconhecido como referência.

A Itália é considerada o país pioneiro na orientação inclusivista e esse percurso iniciou a partir de iniciativas sociais, políticas e históricas e modificações estruturais nas mais diversas instâncias.

Segundo Rodrigues (2005), a Lei no 517 de 1977 (ITALIA, 1977) e a Lei Basaglia, de 1978, são consideradas importantes nesse contexto, sendo resultados de um processo de diversas experiências e lutas anteriores, caracterizados pela transformação de uma Itália camponesa em industrial.

A primeira lei, que tratava da integrazione scolastica, promulgou o processo de extinção das classes de recuperação e das classes diferenciais, propondo a integração nas classes regulares dos estudantes com diferenças em seu processo de escolarização. A lei garantiu a presença de professores especializados para apoio (professor de apoio ou insegnante di sostegno no ensino fundamental e no ensino médio junto do educador profissional (educatore profissionale); o número máximo de vinte alunos nas classes em que houvesse um aluno com deficiência e a formação específica de docentes, abordando de forma ampla o tema da diversidade e da inclusão (RODRIGUES, 2005).

A segunda lei excluiu os manicômios e é considerada por Rodrigues (2005) como background para a abertura à diversidade na sociedade italiana. Apesar dos encaminhamentos ocorridos desde 1977, foi somente em 1992, com a Lei n 0104 (ITÁLIA, 1992), que prevê a frequência de todos os alunos, infra ou normodotados intelectualmente na mesma classe, do maternal à universidade, até os espaços profissionais, que as pessoas com deficiência tiveram a garantia de acesso e permanência às escolas regulares.

Dessa forma, a construção política na Itália foi radical quanto à escolarização das pessoas com deficiência, sendo que até os dias atuais há prioridade absoluta às situações de inclusão e inexistência de estruturas diferenciadas, como classes ou escolas especiais (BAPTISTA, 2001).

Rahme (2013) refere que a reforma educacional na Itália tem sido acompanhada de uma legislação que considera a escola e a sociedade como um todo. Cita como desdobramentos legislações que dispõem sobre a entrada dos alunos na universidade, orientam sobre a promoção e inserção desse grupo no mundo do trabalho e sobre o sistema integrado de intervenção do serviço social em colaboração com a escola.

Informa Rodrigues (2005) que segundo a Lei no 104 (ITALIA, 1992) a pessoa com deficiência é aquela que apresenta alguma limitação física, psíquica ou sensorial, estável ou progressiva, que causa dificuldade de aprendizagem, de relacionamento ou de integração no trabalho, a ponto de determinar um processo de desvantagem social ou marginalização. A lei garante pleno respeito à dignidade e aos direitos, liberdade e autonomia às pessoas com deficiência. Também promove a integração na família, na escola, no trabalho e na sociedade e remove condições invalidantes que impedem o desenvolvimento e a autonomia, assegura a participação na coletividade, bem como a realização de seus direitos civis, políticos e patrimoniais.

Assegura também a recuperação funcional e social através de serviços de prevenção, cura 
e reabilitação, além da tutela jurídica e econômica, também garantindo ações voltadas à superação da marginalização e da exclusão social (RODRIGUES, 2005).

A legislação prevê auxílio sócio-psico-pedagógico - que envolve a estimulação para o desenvolvimento integral do sujeito através de ações terapêuticas e socializadoras -, apoio ao cumprimento de exigências escolares, estímulo ao exercício físico, dentre outras modalidades possíveis de intervenção. Garante também apoio doméstico às famílias com poucos recursos, do tipo assistencial e/ou ligado às tarefas domésticas e operacionais, e auxílio econômico, através de bolsas de estudo, bônus para compra de livros, alojamentos em casas subsidiadas pelo estado pensão de invalidez, dentre outras garantias.

O perfil dinâmico funcional (PDF) da pessoa com deficiência é construído a partir de avaliação multidisciplinar, realizada por profissionais da rede pública de saúde. Após diagnóstico e prognóstico, é elaborado um programa personalizado envolvendo escolas, profissionais e instituições qualificadas para o trabalho com a pessoa. A garantia de seus direitos é preservada se passar por esse processo, conforme Rodrigues (2005). As reavaliações são realizadas em três momentos, aos 10, 14 e aos 18 anos.

Informa Rodrigues (2005) que como forma de atender às demandas das escolas e das famílias foram criadas cooperativas sociais, formadas por profissionais da educação, psicologia, psicomotricidade e outros, que desenvolvem juntamente com os professores o trabalho de integração das crianças e adolescentes de classes públicas ou privadas, pessoas com deficiência visual, motora, intelectual.

As instituições especiais atuam em turno inverso, integradas às escolas, auxiliando nas tarefas de autonomia, aulas de computação, estimulação psicosensorial, apoio psicológico, pedagógico e psicomotor. Há instituições que se ocupam das questões profissionalizantes das pessoas com deficiência, preparando-as e integrando-as ao mercado de trabalho. O trabalho amplia-se e adequa-se de acordo com as necessidades dos estudantes (RODRIGUES, 2005).

Valadão (2010) cita que a Lei 104 (ITALIA, 1992) também prevê o Programa de Educação Individual (PEI), garantido pelo sistema educacional a todos os estudantes em situação de deficiência. O PEI indica características físicas, psíquicas, sociais e afetivas do estudante, apontando limites e possibilidades consequentes da situação de deficiência. O PEI deve estar de acordo com os objetivos educacionais, orientados para atender as capacidades, habilidades e potencialidades dos estudantes em situação de deficiência, incluindo objetivos didáticos de reabilitação, aspectos sociais e de bem-estar.

Segundo Di Pasquali e Maselli as ações concretas do PEI implicam:

[...] - ações para a coleta de dados e informações úteis (observação sistemática, reuniões iniciais e periódicas com a família e com os técnicos, atividades de acolhimento);

- organização flexível e articulada (aulas abertas, grupos de nível, trabalhos em pares, grupos de interesse, uso de laboratórios, aprendizagem cooperativa, uso de autoria);

- estratégias para facilitar a aprendizagem. A presença de um aluno com deficiência torna-se a força propulsora para a ativação de mudanças que alteram o trabalho dentro da sala de aula, e tem também um impacto maior sobre as escolhas educacionais tomadas.

[...] é necessária a referência à avaliação concebida como ferramenta inevitável para a melhoria dos projetos individuais e da escola, portanto, como parte integrante do PEI. A avaliação não deveria ser apenas o teste 
contínuo e final sobre o que foi construído em relação à aprendizagem, mas deveria envolver também atenção dirigida aos progressos realizados nas áreas de autonomia, comunicação, relacionamento. (DI PASQUALI; MASELLI, 2014, p. 717)

A ideia é facilitar a aprendizagem, com diversidade de condições, juntamente com atividades extracurriculares, para favorecer a transição para o trabalho, a vida adulta e escola técnica ou ensino superior universitário. A idade ou etapa da escolarização são menos relevantes, sendo prioridade as atividades educativas com flexibilidade, a fim de implementar o programa escolar e garantir a continuidade educativa entre os níveis de ensino, exigindo colaboração entre os professores em diferentes níveis. Valadão (2010) refere que no trabalho interdisciplinar da proposta educacional inclusiva italiana profissionais especialistas em inclusão escolar colaboram na elaboração dos PEI. Os planos são coordenados entre serviços escolares, saúde, serviço social, cultura, lazer, centros esportivos, órgãos públicos e privados.

Somado ao trabalho pedagógico diferenciado, a organização do sistema educativo é dividido em maternas, onde as crianças permanecem dos 3 aos 5 anos. Após, os períodos são divididos em três momentos, quais sejam: Escola Primária (Scuola primaria) - para crianças dos 6 aos 10 anos; Escola Secundária de Primeiro Grau (Scuola secondaria di primo grado) -dos 11 aos 14 anos e; Escola Secundária de segundo grau (Scuola secondaria di scondo grado) - dividida em Liceo (formação de cunho geral - 5 anos) ou formação técnico profissionalizante -3 anos. (GREGUOL; GOBBI; CARRARO, 2013). Valadão (2010) relata que na faixa etária de 0 a 3 anos alunos com deficiência têm vaga garantida em creches e assim consecutivamente. Avançando nos ní- veis escolares terão garantidas vagas na escola primária, secundária e posteriormente ingresso no ensino superior. Baptista (2001) afirma que a divisão do ensino secundário em formação ampla ou técnico profissionalizante favorece as pessoas com deficiência, especialmente aquelas com deficiência intelectual, que se beneficiam da formação técnica, direcionada em função de habilidades e possibilidades particulares.

A formação docente tem relação com os diferentes períodos em que o professor trabaIha. São exigidas e oferecidas formações específicas para atuação com estudantes com deficiência. Para o ensino primário é necessária formação acadêmica superior de no mínimo cinco anos; para o secundário é indispensável o curso superior e graduação em alguma área específica do conhecimento, tendo o docente oportunidade, como ampliação da formação, de cursar especialização em ensino de apoio (GREGUOL; GOBBI; CARRARO, 2013).

Segundo Greguol, Gobbi e Carraro (2013), em 2010 houve um salto qualitativo na formação de professores, pois passaram a ser exigidos pela legislação, na formação universitária, conteúdos específicos de Didática e Pedagogia Especial. Também foi adicionado o Estágio Formativo Ativo, com um mínimo de 75 horas dedicadas ao aprimoramento das competências didáticas para a inclusão dos alunos com deficiência. A formação do professor de apoio é mais aprofundada, sendo exigidos 60 créditos formativos (1500 horas), dos quais 12 (600) dedicados aos estágios específicos na escola.

Em dezembro de 2012 ocorreram modificações nos dispositivos legais italianos acerca da inclusão. Greguol, Gobbi e Carraro (2013) citam a ampliação do conceito de Necessidades Educativas Especiais, que anteriormente só compreendia as pessoas com deficiência 
e atualmente contempla transtornos globais do desenvolvimento e outras dificuldades de aprendizagem.

Os autores também destacam a formalização dos Centros Territoriais de Apoio (Centri Territoriali di Supporto - CTS) que, em consonância com os Centros Territoriais para a Inclusão (Centri Territoriali per l'Inclusione - CTI) - serviço de informações às famílias, estudantes, professores, entre outros), provêm apoio às escolas com informações e atualizações de recursos, tecnologias facilitadoras e outros aspectos que favoreçam a inclusão. Ambos oferecem cursos de capacitação docente e atualizações técnicas de recursos que estejam disponíveis para os estudantes com deficiência (GREGUOL; GOBBI; CARRARO, 2013).

Pode-se observar que a proposta educacional inclusiva italiana possui um histórico amplo e caráter inovador em relação a outros países, embora alguns estudos e dados indiquem que existem desafios presentes nesse modelo.

Rahme (2013) comenta que a articulação entre os processos individuais desenvolvidos com os alunos com deficiência e o processo coletivo da turma podem ser qualificados, sugerindo que as dinâmicas sejam menos tecnicistas e solitárias. Problematiza também questões referentes ao professor especializado de apoio, como se esse fosse a única alternativa a ser considerada diante de um estudante deficiente e o único responsável pela sua integração nas classes regulares.

A partir dessas considerações explicitou-se algumas características do modelo educacional italiano de educação inclusiva.

\section{Aproximações e Distanciamentos Entre os Modelos Brasileiro e Ital- iano de Educação Inclusiva}

A inclusão é um conceito que tem provocado movimentos constantes nas diferentes sociedades nas dimensões filosóficas, políticas, econômicas, relacionais, pessoais e educacionais. Traz em sua proposta uma característica que mobiliza o pensar, o agir e o sentir coletivo. A presença da complexidade e da diferença fundamentada em uma concepção de direitos humanos, que conjuga igualdade de oportunidades e qualidade nas aprendizagens, promove avanços em relação às circunstâncias históricas de exclusão vivenciadas dentro e fora da escola.

Para Sánchez (2005) incluir supõe o dever de condicionar as decisões e ações de todos os participantes do sistema de ensino, já que o termo incluir, em sua origem, significa ser parte de algo, formar parte do todo, enquanto excluir significa manter fora, apartar, expulsar.

Considera a autora:

Educação inclusiva é antes de tudo uma questão de direitos humanos, já que defende que não se pode segregar a nenhuma pessoa como consequência de sua deficiência, de sua dificuldade de aprendizagem, do seu gênero ou mesmo se esta pertencer a uma minoria étnica $[. .$.$] é uma atitude, representa$ um sistema de valores e de crenças, não uma ação simplesmente, mas sim um conjunto de ações. (SÁNCHEZ, 2005, p. 12)

Mittler (2003) argumenta que o conceito de inclusão envolve um repensar radical da política e da prática e seu objetivo está no coração da política social. Quanto à educação, considera que, para garantia do acesso e participação educacional e social de todos e para impedir a 
segregação e isolamento, é necessário um processo de reforma e estruturação das escolas como um todo, incluindo currículo, avaliação, registros, agrupamentos, propostas pedagógicas, práticas de sala de aula e oportunidades de esporte, lazer e recreação.

Os modelos de inclusão educacional que vêm se desenvolvendo no Brasil e na Itália apresentam como aproximações o fato de serem signatários das resoluções internacionais e apresentarem mudanças legislativas em seus movimentos. Porém, os trajetos temporais, as características e as práticas políticas, sociais e pedagógicas são diferenciadas, como até aqui explicitado.

No Relatório Técnico de Políticas Públicas de Educação Especial (PORTUGAL, 2014), segundo a classificação da Associação Europeia para - Desenvolvimento da Educação Especial, os países são agrupados com base na caracterização de suas políticas de integração/inclusão de alunos com necessidades educativas especiais em três categorias:

a) One Track Approach - países de trajetória única e que possuem práticas orientadas para a inclusão de todos os alunos no sistema regular de ensino;

b) Multi Track Approach - países que seguem uma abordagem múltipla para a inclusão, isto é, integram o sistema de educação especial e o sistema regular;

c) Two Track Approach - países onde existem dois sistemas educativos distintos e os alunos com necessidades educativas especiais frequentam escolas especiais com currículo específico.

Segundo essa classificação, a Itália, em função de sua trajetória histórica e sistema educativo, está inserida na primeira categoria. O Brasil, caso participasse da classificação europeia, ocuparia a segunda categoria, por apre- sentar abordagem múltipla para estudantes com deficiência, os quais participam dos sistemas de educação especial e da escola regular.

Chagas (2006) apresenta referências da percepção internacional sobre a questão da deficiência no Brasil, informando que segundo o relatório de Monitoramento Internacional dos Direitos dos Deficientes, realizado pelo Centro para Reabilitação Internacional, o Brasil está entre os cinco países mais inclusivos das Américas. O relatório avaliou os países em relação ao apoio a tratados internacionais, oportunidades de educação e emprego, mobilidade, serviços de saúde e moradia e facilidade de comunicação, classificando-os em mais inclusivos, moderadamente inclusivos e menos inclusivos. É evidente que as classificações não tornam os países mais inclusivos em sua plenitude, nem supõem permanências, pois muitas das diretrizes legais inclusivas existentes nas legislações não asseguram mudanças na sociedade. Contudo, as diretrizes legislativas e os movimentos em prol da inclusão são passos iniciais em direção ao incluir na sociedade como um todo.

Elencando elementos para aproximação, distinção e compreensão dos modelos, é possível citar que a trajetória histórica é um dos aspectos que distingue os modelos brasileiro e italiano, já que a Itália tem a inclusão como diretriz fundamental para toda a educação nacional desde 1977, com a Integrazione Scolastica, sendo um dos países reconhecidos como referência na atualidade. Nesse país, a educação inclusiva faz parte de um plano de vida e sua constituição tem relação com a construção da participação ativa da pessoa com deficiência na vida social (DI PASQUALE; MASELLI, 2014).

No Brasil, a trajetória é mais recente, percebendo-se mais movimentos, especialmente políticos, a partir da década de noventa. Chagas (2006) refere que a atenção explícita das 
ações públicas governamentais às pessoas com deficiência são contemporâneas. Quanto à questão educacional no Brasil, apesar do que a legislação assegura, aparentemente poucos avanços foram contabilizados e a inclusão em diferentes níveis da educação básica é uma realidade ainda distante (PASSERINO; PEREIRA, 2014).

Beyer (2009) afirma também que a escola inclusiva brasileira está em crise de consolidação, encontrando-se diante de um movimento quanto ao projeto da educação inclusiva, porém com descompassos entre a política educacional nacional e a realidade educacional brasileira.

Nesse aspecto pode-se refletir acerca dos direitos humanos, os quais são categorias legais de validade universal, embora sigam itinerários incomuns nas diferentes culturas. Da mesma forma, a existência das normas referentes à inclusão não corresponde a sua observância. Chagas (2006) cita alguns aspectos impeditivos à formulação e implementação de políticas no Brasil, que têm relação com o governo e a sociedade: insensibilidade humanitária, falta de prioridade política, desconhecimento legal ou técnico, falta de recursos para abranger toda a população.

Di Pasquali e Maselli refletem sobre a realidade italiana e afirmam que, apesar do processo de inclusão escolar se desenvolver de forma decidida, apresenta descontinuidades e reflexos da radicalidade até os dias atuais:

[...] as condições extremamente heterogêneas do território italiano, os altos e baixos de políticas de apoio ao sistema de ensino como um todo e a retirada dos recursos públicos tiveram um impacto significativo sobre as condições reais da tradução dos princípios orientadores em práticas educativas cotidianas que contribuíram para delinear um quadro heterogêneo, desigual, que apresenta situações de excelência e de boa qualidade e outras certamente muito mais críticas e merecedoras de atenção (DI PASQUALI; MASELLI, 2014, p. 708).

Rahme (2013) aponta aspectos que constituem desafios presentes no modelo italiano como a superação de posturas pedagógicas tecnicistas e redução dos percursos de trabalho solitários nas escolas. Relata que algumas práticas ainda acontecem de forma isolada, automática, sem a participação coletiva dos professores e entre os estudantes. Sugere avanços no posicionamento dos professores de apoio no contexto da sala de aula e da escola e a evolução do modelo médico de deficiência, o qual enfatiza as falhas, sendo que esse ainda persiste na realidade italiana.

Um aspecto conceitual da legislação e da prática inclusiva na Itália que se aproxima com a brasileira é ligado às identificações e classificações referentes ao público com necessidades educativas especiais (NEE) (GREGUOL; GOBBI; CARRARO, 2013). Para Di Pasquali e Maselli (2014), ambos os países são regidos por diagnósticos, porém, com diferenças que norteiam o processo de incluir como explicitado a seguir.

No Brasil são atendidos no regime da Educação Especial (AEE nas SRM) pessoas com deficiência, portadores de altas habilidades e de transtornos globais do desenvolvimento.

Na Itália, a classificação compreende três categorias:

a) Categoria $A$ - alunos com deficiência (derivadas de limitações orgânico-funcionais atribuíveis à deficiência ou doenças orgânicas de origem sensorial, motora ou neurológica);

b) Categoria $B$ - alunos com dificuldades emocionais e comportamentais ou Transtornos Específicos de Aprendizagem - TEA - (como dislexia, inserida recentemente); 
c) Categoria $C$ - alunos com desvantagens associadas ao ambiente socioeconômico, cultural e sociolinguístico de origem.

Apesar da aproximação por categorização entre os modelos brasileiro e italiano, há diferenças relacionadas ao modelo italiano por basear-se na Classificação Internacional de Funcionalidade, Incapacidade e Saúde (CIF) (OMS, 1989), quadro de referência utilizado para descrever, avaliar e medir saúde e incapacidade. Ela apresenta modelos ligados à saúde e doença, porém com associação de níveis interacionais complexos entre múltiplos fatores, como atividades e participação possíveis para pessoas com deficiência na perspectiva biológica, social e psicológica, intimamente ligadas e interdependentes (DI PASQUALI; MASELLI, 2014).

Quanto às particularidades referentes à escola, a garantia de redução do número de alunos no grupo com presença de uma pessoa com deficiência é uma das diretrizes diferenciais. A legislação italiana assegura o limite máximo de vinte crianças e prevê a presença do professor especializado de apoio, com formação acadêmica específica referente ao nível em que leciona, que atua conjuntamente com o professor regente da turma, caracterizando a bidocência. Di Pasquali e Maselli (2014) aludem à relação entre o aluno e o professor de apoio, na qual pode ocorrer ênfase excessiva sobre o profissional, reduzindo oportunidades de atuação com toda a classe, podendo haver isolamento do aluno e do professor, minimizando a pluralidade do processo, princípio do modelo inclusivo italiano.

Greguol, Gobbi e Carraro (2013) apresentam dados que indicam que a realidade apresenta distanciamentos em relação à legislação quanto ao número máximo de alunos em sala de aula, pois há denúncias de irregularidades, apontadas no relatório de educação especial. Problemas de acessibilidade arquitetônica de muitas instalações escolares e carência de recursos materiais adequados também são problemas na realidade inclusiva italiana.

Valadão (2010) associa informações que relatam a existência de escolas para cegos e surdos e outros com fala comprometida, bem como escolas com metas específicas para educação especializada em deficiências físicas e dificuldades graves.

Di Pasquali e Maselli (2014) ressaltam outro aspecto diferencial na prática educativa italiana: a utilização do PEI, um planejamento individualizado multiprofissional, formado pelo diagnóstico funcional, perfil dinâmico-funcional, lista de atividades educativas organizadas em função das necessidades educativas do aluno e critérios de avaliação adequados à situação pessoal. Na busca do equilíbrio das ações pedagógicas, o PEI promove o direito a um plano educativo que responda às necessidades diferenciadas e desenvolvimento de competências de todos os estudantes com deficiência, orientando-os na escola, articulando programação comum, atividades personalizadas e percursos individuais.

Valadão (2010) cita que nesses casos o desenvolvimento psicofísico é mais importante do que a etapa ou fase de escolarização, podendo o estudante seguir o currículo padrão ou simplificado de acordo com suas habilidades.

No Brasil, existe o AEE como modalidade de Educação Especial para as pessoas com NEE. Constitui um trabalho docente paralelo ao trabalho da classe regular, que ocorre nas SRM. Garcia (2013) assinala que tal serviço representa uma complementaridade formal, pois não se constitui em serviço articulado com o trabalho desenvolvido na sala comum, sendo 
fonte de separação e pouco incidindo sobre o processo de escolarização dos sujeitos na modalidade Educação Especial. Ao mesmo tempo é a possibilidade de intervenção particularizada oferecida atualmente às pessoas com deficiência.

A colaboração entre escola e família no modelo italiano é outro indicador a ser considerado. A família é vista como ponto de referência essencial, fonte de informações e interlocutor protagonista para o planejamento do projeto de vida da pessoa com deficiência.

Conforme Di Pasquale e Maselli (2014) esse aspecto é de exigência constante e contínua na legislação. O respeito mútuo, a compreensão das diferentes funções, a garantia da expressão e compartilhamento dos fins educativos, dos respectivos papéis e responsabilidades constituem um dos focos da política e das ações que têm como finalidade incluir em todas as instâncias.

A intersetorialidade, vista como a articulação de ações efetivas entre os diversos setores públicos, é mais uma característica que se apresenta drasticamente distinta nos dois modelos. Na realidade italiana há um programa de inclusão, onde se visualiza e se vive a participação coletiva e a corresponsabilidade. As políticas educativas têm relação com os sistemas de saúde, assistência social, esporte, lazer, ou seja, contemplam todas as dimensões da vida das pessoas com deficiência e o acompanhamento acontece desde a identificação da deficiência. O PEI e o PDF, bem como os centros de atenção, são exemplos de ações efetivas dessa dimensão do modelo italiano.

Góes e Machado (2013) afirmam que as políticas sociais em curso no Brasil têm evidenciado a ausência de ações integradas e de transformações sociais. Não há articulação, integração, diálogo, nem esforço institucionali- zado e sistemático de compatibilização de atuações complementares.

A fragmentação é a forma como as organizações setoriais tratam os cidadãos e seus problemas, oferecendo serviços isoladamente. As ações públicas têm sido restritas, predominando na área da Assistência Social. Há iniciativas públicas em outros níveis federados, parcerias entre o governo, entidades não-governamentais e instituições particulares (GÓES; MACHADO, 2013).

Tais entidades e instituições têm perfis variados e atuações orientadas para finalidades diversas, que vão desde o modelo assistencialista até o incentivo à busca da cidadania e inclusão social. Porém, existe uma distância quanto à possibilidade de participação nos vários aspectos da vida da comunidade, recebimento de atenção médica, psicológica e funcional adequadas, educação, formação e readaptação profissional, especialmente em relação à transversalidade necessária ( $\mathrm{CHA}$ GAS, 2006).

Além da falta de articulação entre as diferentes esferas públicas, observa-se que no Brasil não há um requisito legal que assegure parâmetros mais específicos sobre conteúdos mínimos necessários na formação de professores, nem esclarecimentos sobre a formação do profissional da Educação Especial. Também há dificuldades e lacunas em termos práticos nas escolas, especialmente no desenvolvimento das competências didáticas e na avaliação das pessoas com deficiência.

Greguol, Gobbi e Carraro, sobre a formação de professores da Educação Especial, afirmam:

A lacuna existente entre a formação e a atuação prática tem feito com que os professores sintam-se perdidos diante da missão de lidar com a diversidade em sala de aula, sobretudo pela falta de conhecimento de como 
adaptar as atividades, materiais, conteúdos programáticos ou procedimentos de ensino. (GREGUOL; GOBBI; CARRARO, 2013, p. 312)

Ainda, estudo comparativo das legislações brasileira e italiana sobre educação especial desde a década de setenta, realizado por $\mathrm{Ca}$ bral, afirma:

[...] enquanto o Brasil instituiu dispositivos legais e normas para incentivar mudanças, na Itália, as normas eram instituídas coletivamente para fundamentar práticas já existentes; a perspectiva médica para a identificação do alunado na Itália reduz para 1,5\% a população a ser atendida, o que no Brasil é estimado em 14,5\%, influenciando diretamente na canalização dos investimentos em educação para esse segmento populacional, dentre outros serviços; enquanto as famílias italianas reivindicaram a educação dos seus filhos nos espaços comuns da sociedade, no Brasil, a luta foi para o funcionamento de instituições especializadas; por mais que a inclusão escolar na Itália seja considerada uma experiência política mais radical no âmbito mundial, ainda assim reconhece a necessidade de manutenção do funcionamento das instituições especializadas para surdos e cegos; em ambos os contextos identificam-se dificuldades de articulação entre os serviços da saúde e da educação e permanece a tendência comum dos professores das classes comuns de delegar a responsabilidade do ensino do aluno com deficiência ao professor especializado. (VALADÃO apud VALADÃO, 2010, p. 53)

Observa-se que dimensões éticas, pedagógicas, sociais, políticas, econômicas, dentre outras, caracterizam o ato de incluir e sua efetividade enquanto ato democrático de busca de igualdade de direitos e oportunidades.

Aspectos ligados à historicidade e estruturas legais confirmam o caminho específico de cada sistema inclusivo. Heterogeneidade no público, nos contextos, nos tempos e nas práticas definem o incluir em seus diferentes modelos e modalidades. Trata-se de um desafio, que engloba envolvimento, comprometimento e responsabilidade de toda a sociedade.

\section{Considerações Finais}

O movimento mundial em direção a reflexões, discussões e ações no que se refere à inclusão e à educação na perspectiva inclusiva é permanente. Cada nação carrega consigo sua história, sua forma de construir tal processo, com características peculiares referentes à sociedade, dinâmicas governamentais, constituição espaço-temporal, economia, dentre outros fatores intervenientes.

O Brasil e a Itália são países que se aproximam em alguns aspectos e se distanciam substancialmente em outros. Ambos possuem fatores positivos e fatores a serem observados, avaliados e revisados, constituindo a continuidade do processo que caracteriza as grandes mudanças conceituais, culturais e práticas ocorridas até hoje, em nível internacional.

Observou-se no estudo que alguns aspectos podem ser considerados como referência na discussão entre os modelos brasileiro e italiano. Em ambos os países observa-se avanços legislativos, crescente ingresso e permanência de estudantes com deficiência nos ambientes escolares, investimento em formação de professores, porém as ações não garantem total qualidade na efetividade das realidades ditas inclusivas, especialmente no Brasil.

Modelos perfeitos e terminados não seriam condizentes com o pressuposto básico da inclusão, o qual é baseado no acolhimento, aceitação e convivência construtiva diante das diferenças; porém, é nas diferenças que 
se baseiam as possibilidades de constituição de novas formas de ser, fazer, estar e sentir na sociedade. Dessa forma, características como prévio acompanhamento biopsicossocial das pessoas com deficiência, definição do público alvo, existência e revisão constante dos planejamentos individualizados, formação de professores plenamente caracterizada e com exigência de perfil acadêmico, parceria entre instituições e famílias e políticas públicas articuladas são pontos do modelo inclusivo italiano que podem colaborar para a reflexão e busca de novas possibilidades à realidade do modelo brasileiro.

A ampliação do olhar atento e crítico para tal situação é emergencial, pois é preciso considerar a necessidade e a relevância social, política, educativa, familiar e particular de cada uma das pessoas com deficiência em seus contextos.

Da mesma forma, apoiados em um modelo de inclusão que tem em sua trajetória décadas de experiência e na busca pelas reais possibilidades de igualdade no tratamento e oportunidades de todos, fica evidente que é imprescindível a revisão das formas de condução das políticas públicas no Brasil. Investimentos no quesito da intersetorialidade, imprimindo esforços de ligação e interligação das legislações, políticas e ações concretas são algumas diretrizes que podem conduzir a uma evolução no processo do incluir na sociedade brasileira.

Também é imprescindível a formação de professores que busquem a transformação dos conceitos, dos posicionamentos subjetivos e que vão além na reflexão e conscientização so- bre o processo de incluir. Esses são indicadores qualitativos de uma educação inclusiva, assim como o fato de se reduzir distâncias entre as previsões legais e as práticas cotidianas, direcionar o olhar para todas as dimensões da vida das pessoas com deficiência, articulando-as objetivamente para alcançar eficácia e eficiência concretas. Essas considerações, atitudes e propostas são focos centrais de sucesso dos projetos de inclusão social e educacional.

A qualidade de vida, o desenvolvimento biopsicossocial pleno, a convivência saudável e a autonomia constituem direitos humanos universais. Em busca de uma nova proposição sócio histórica que busca incluir, percebe-se modificações em prol da inclusão social, bem como, concomitantemente, a conservação de muitas práticas ligadas à cultura da normalização e da igualdade social reprodutiva presentes na sociedade até os dias atuais.

Considerando esses fatos, acolher a presença integral do outro, promover a verdadeira atenção à complexidade e heterogeneidade, buscar a qualificação do exercício de cidadãos que buscam viver e conviver em harmonia, dialogando e complementando histórias e experiências, constituem alguns dos desafios impostos.

Conhecer e reconhecer as aproximações e distanciamentos que caracterizam os modelos inclusivos das diversas sociedades pode tornar-se um exercício reflexivo e um passo em direção ao reconhecimento positivo, somando novos passos à caminhada, a qual possibilita rumar a novas descobertas e para a construção de outros itinerários. 


\section{Referências}

BAPTISTA, Claudio Roberto. A Integração dos Alunos Portadores de Deficiência e o Atual Contexto Educacional Italiano. In: EDUCAÇÃO on-line. [site]. [S.I.: s.n.], 2001. Disponível em: <http://www. educacaoonline.pro.br/index.php?option =com_content\&view=article\&id=106:a-integracao-dos-alunos-portadores-de-deficiencia-e-o-atual-contexto-educacionalitaliano\&catid=6: educacao-inclusiva\&Itemid=17> Acesso em: 2 jul. 2014.

BEYER, Hugo Otto. O Projeto da Educação Inclusiva: perspectivas e princípios de implementação. In: JESUS, Denise Meyrelles de et al. (Org.). Inclusão, Práticas Pedagógicas e Trajetórias de Pesquisa. Porto Alegre: Mediação, 2009. P. $75-81$.

BRASIL. Congresso Nacional. Constituição da República Federativa do Brasil. Brasília: Senado Federal; Centro Gráfico, 1988.

BRASIL. Declaração de Salamanca e Linha de Ação Sobre Necessidades Educativas Especiais. Brasília: CORDE, 1994.

BRASIL. Lei n. 4.024, de 20 de dezembro de 1961. Fixa as Diretrizes e Bases da Educação. In: BRASIL. Câmara dos Deputados. Legislação. Brasília, 1961. Disponível em: <http://www2.camara.leg.br/legin/fed/lei/1960-1969/lei-4024-20-dezembro-1961-353722-publicacaooriginal-1-pl.html> Acesso em: 2 jul. 2014.

BRASIL. Lei no 9.493, de 20 de dezembro de 1996. Estabelece as diretrizes da educação Nacional. Brasília, 1996.

BRASIL. Congresso Nacional. Plano Nacional de Educação. Brasília, 2001. Disponível em: <http:// www.planalto.gov.br/ccivil_03/leis/leis_2001/l10172.htm> Acesso em: 24 jun. 2014.

BRASIL. Ministério da Educação. Secretaria da Educação Especial. Diretrizes Operacionais para o atendimento educacional especializado na Educação Básica, modalidade Educação Especial. Brasília, 2009. Disponível em: <http://portal.mec.gov.br/dmdocuments/pceb013_09_homolog.pdf> Acesso em 29 de junho 2014.

BRASIL. Ministério da Educação. Secretaria de Educação Especial. Política Nacional de Educação Especial. Brasília: MEC/SEESP, 1994.

BRASIL. Ministério da Educação. Secretaria de Educação Especial. Política Nacional de Educação Especial na Perspectiva da Educação Inclusiva. Brasília: MEC/SEESP, 2007. 
BRASIL. Ministério da Educação. Secretaria de Educação Especial. Política Nacional de Educação Especial na Perspectiva da Educação Inclusiva. Brasília, 2008. Disponível em: < http://portal.mec. gov.br/arquivos/pdf/politicaeducespecial.pdf> Acesso em: 28 jun. 2014.

BRASIL. Ministério da Educação. Secretaria de Educação Básica. Política Nacional de Formação de Profissionais do Magistério da Educação Básica. Brasília, 2012. Disponível em: <http://sinafor. mec.gov.br> Acesso em: 2 jul. 2014.

CABRAL, Leonardo Santos Amâncio. A Legislação Brasileira e Italiana Sobre a Educação Especial: da década de 1970 aos dias atuais. 2010. Dissertação (Mestrado) - Programa de Pós-graduação de Educação Especial, Universidade Federal de São Carlos, 2010, São Carlos, BR-SP. Disponível em: <http://www.bdtd.ufscar.br/htdocs/tedeSimplificado//tde_busca/arquivo.php?codArquivo=3018> Acesso em: 2 jul. 2014.

CARVALHO, Rosita Edler Educação Inclusiva: com os pingos nos "is". Porto Alegre: Mediação, 2004.

CHAGAS, Ana Maria de Resende. Avanços e Impedimentos Para a Construção de uma Política Social Para as Pessoas com Deficiência. 2006. Dissertação (Mestrado) - Departamento de Serviço Social, Universidade de Brasília, 2006, Brasília, BR-DF. Disponível em: <http://repositorio.unb.br/handle/10482/5746> Acesso em: 2 jul. 2014.

DI PASQUALI, Giovanna; MASELLI, Marina. Pessoas com Deficiência e Escola: principais mudanças na experiência italiana. Educação \& Realidade, Porto Alegre, v. 39, n. 3, p. 707-724, jul./set. 2014. Disponível em: <http://seer.ufrgs.br/index.php/educacaoerealidade/article/view/46313> Acesso em 2 de julho de 2014.

GARCIA, Rosalba Maria Cardoso. Política de Educação Especial na Perspectiva Inclusiva e a Formação Docente no Brasil. Revista Brasileira de Educação, Curitiba, v. 18, n. 52, p. 101-122, jan./mar. 2013. Disponível em: <http://www.scielo.br/pdf/rbedu/v18n52/07.pdf> Acesso em: 2 jul. 2014.

GÓES, Flávia Temponi; MACHADO, Lucília Regina de Souza. Políticas Educativas, Intersetorialidade e Desenvolvimento Local. Educação \& Realidade, Porto Alegre, v. 38, n. 2, p. 627-648, abr./jun. 2013. Disponível em: <http://seer.ufrgs.br/educacaoerealidade/article/view/21891> Acesso em: 2 jul. 2014.

GREGUOL, Márcia; GOBBI, Erica; CARRARO, Attilio. Formação de Professores Para a Educação Especial: uma discussão sobre os modelos brasileiro e italiano. Revista Brasileira de Educação Especial, Marília, v. 19, n. 3, set. 2013. Disponível em: <http://www.scielo.br/scielo.php?script=sci_arttext\&pid= S141365382013000300002\&lng=pt\&nrm=iso\&tlng=pt> Acesso em: 2 jul. 2014. 
ITALIA. Legge n. 104, de 05 de fevereiro de 1992. Roma, 1992. Disponível em: <http://www.pubblica.istruzione.it/dgstudente/disabilita/allegati/legge104.pdf> Acesso em: 2 jul. 2014.

ITALIA. Legge n. 517, de 04 de agosto 1977. Roma, 1977. Disponível em: <http://www.pubblica. istruzione.it/dgstudente/disabilita/allegati/legge517.pdf> Acesso em: 2 jul. 2014.

KASSAR, Mônica de C.M. Percursos da Constituição de uma Política Brasileira de Educação Especial Inclusiva. Revista Brasileira de Educação Especial, Marília, v. 17, p. 41-58, 2011.

MITTLER, Peter. Educação Inclusiva. Porto Alegre: Artmed, 2003.

OEA. Convenção Interamericana Para a Eliminação de Todas as Formas de Discriminação Contra as Pessoas Portadoras de Deficiência. Guatemala, 1999. Disponível em: <http://portal. mec.gov.br/seesp/arquivos/pdf/guatemala.pdf> Acesso em: 2 jul. 2014.

OMS. Classificação Internacional das Deficiências, Incapacidades e Desvantagens Handicaps: um manual de classificação das consequências das doenças. Lisboa, 1989.

ONU. Declaração Universal dos Direitos Humanos. 1948. Disponível em: <http://portal.mj.gov.br/ sedh/ct/legis_intern/ddh_bib_inter_universal.htm> Acesso em: 2 jul. 2014.

ONU. Convenção Sobre os Direitos das Pessoas com Deficiência. Nova Iorque, 2006. Disponível em: <http://www.mpgo.mp.br/portalweb/hp/41/docs/comentarios_a_convencao_sobre_os_direitos_ das_pessoas_com_deficiencia.pdf> Acesso em: 2 jul. 2014.

PASSERINO, Liliana M.; MONTARDO, Sandra Portella. Inclusão Digital e Acessibilidade Digital: interfaces e aproximações conceituais. Trabalho apresentado ao Grupo de Trabalho "Comunicação e Cibercultura", do XVI Encontro da Compós, na UTP, em 2007, Curitiba, BR-PR. Disponível em: <http:// redessociaiseinclusao.pbworks.com/f/ID-acess_compos_2007_vers\%C3\%A30+final.pdf> Acesso em: 2 jul. 2014.

PASSERINO, Liliana Maria; PEREIRA, Ana Cristina. Educação, Inclusão e Trabalho: um debate necessário. Educação \& Realidade, Porto Alegre, v. 39, n. 3, p. 831-846, jul./set. 2014. Disponível em: <http://www.scielo.br/pdf/edreal/v39n3/v39n3a11.pdf> Acesso em: 2 jul. 2014.

PORTUGAL. Conselho Nacional de Educação. Relatório Técnico de Políticas Públicas de Educação Especial. Lisboa, 2014. Disponível em: <http://www.cnedu.pt/content/noticias/CNE/RelatorioTecniCo_EE.pdf> Acesso em: 2 jul. 2014. 
RAHME, Monica Maria Farid. Inclusão e Internacionalização dos Direitos à Educação: as experiências brasileira, norte-americana e italiana. Educação \& Pesquisa, São Paulo, v. 39, n. 1, p. 95-110, jan./ mar. 2013. Disponível em: <http://www.scielo.br/pdf/ep/v39n1/v39n1a07.pdf> Acesso em: 30 jun. 2014.

RODRIGUES, Maria Beatriz. Quais são as Nossas Diferenças?: reflexão sobre a convivência com o diverso em escolas italianas. Psicologia \& Sociedade, v. 17, n. 3, p. 57-61, set./dez. 2005. Disponível em: <http://www.scielo.br/pdf/psoc/v17n3/a08v17n3> Acesso em: 2 jul. 2014.

SANCHEZ, Pilar Arnaiz. Educação Inclusiva: um meio de construir escola para todos no século XXI. Inclusão: revista da educação especial, Brasília, n. 1, p. 7-18, out. 2005.

UNESCO. Agência Europeia Para o Desenvolvimento em Necessidades Educacionais Especiais. Educação Inclusiva e Práticas de Sala de aula: relatório Síntese. Odense, 2003. Disponível em: <http:// www.european-agency.org/publications/ereports/inclusive-education-and-classroom-practices/iecp-pt. pdf> Acesso em: 13 jun. 2014.

UNESCO. Declaração Mundial Sobre Educação Para Todos: satisfação das necessidades básicas de aprendizagem. Jomtien, 1990.

VALADÃO, Gabriela Tannús. Planejamento Educacional Individualizado na Educação Especial: propostas oficiais da Itália, França, Estados Unidos e Espanha. 2010. Dissertação (Mestrado) - Programa de Pós-Graduação em Educação Especial, Centro de Educação e Ciências Humanas, Universidade Federal de São Carlos, 2010, São Carlos, BR-SP. Disponível em: <http://www.bdtd.ufscar.br/htdocs/ tedeSimplificado//tde_busca/arquivo.php?codArquivo=3874> Acesso em: 2 jul. 2014.

VALENTINI, Carla; BISOL, Claudia. Inclusão no Ensino Superior: especificidades da prática docente com estudantes surdos. Caxias do Sul: Educs, 2012.

Submetido para avaliação em 13 de dezembro de 2014.

Aprovado para publicação em 31 de março de 2015.

Caroline Carminatti Scussiatto - Universidade de Caxias do Sul (UCS), Universidade Federal do Rio Grande do Sul (UFRGS), Porto Alegre, BR-RS. E-mail: caroline.scussiatto@gmail.com 